\title{
Aplicação de fotocatálise heterogênea e homogênea para a remoção de cor em efluentes provenientes de indústria de procesamento de couro
}

\author{
Heterogeneous and homogeneous photocatalysis application for dye removal in leather tannery wastewater \\ Francisco Teran' \\ 'Professor e pesquisador da Escola de Engenharia Civil, curso de Engenharia Ambiental e Sanitária, Universidade Federal de Goiás, Brasil
}

\section{Resumo}

Este trabalho teve como objetivo o estudo da aplicação de processos oxidativos avançados (POAs) para a remoção de cor em efluente proveniente de indústria de tingimento de couro. Investigou-se, então, a eficácia no tratamento desse efluente utilizando fotocatálise heterogênea com radiação ultravioleta (UV) e catalisador dióxido de titânio imobilizado em placas de vidro, bem como sua comparação com fotoclivagem com peróxido de hidrogênio $\left(\mathrm{H}_{2} \mathrm{O}_{2}\right)$ aliado à radiação UV. A fotocatálise heterogênea se mostrou indiferente para o tratamento do efluente em questão, não obtendo degradação de cor. Entretanto todos os experimentos envolvendo $\mathrm{H}_{2} \mathrm{O}_{2}$ apresentou bons resultados com destaque para o experimento com $1,40 \%$ do oxidante. Nesse caso houve remoção de $96 \%$ na absorbância, $53 \%$ na carga orgânica e $93 \%$ nos sólidos totais.

Palavras-chave: Processos oxidativos avançados. Fotoclivagem com peróxido de hidrogênio. Peróxido de hidrogênio.

\begin{abstract}
The purpose of this work was to study the effects of the application of advanced oxidative processes (POAs) to the removal of dyes in tanning industries effluents. Heterogeneous and homogeneus photocatalysis were tested applying glass-immobilized $\mathrm{TiO}_{2}$ with UV radiation (254 $\mathrm{nm}$ ) and suspended $\mathrm{H}_{2} \mathrm{O}_{2}$ also with UV radiation, respectively in order to obtain comparative results. Heterogeneus photocatalysys showed to be ineffective for dye removal. On the other hand, homogeneus photocatalysis with $\mathrm{H}_{2} \mathrm{O}_{2}$ presented satisfactory results with $96 \%$ removal in absorbance, $53 \%$ removal of organic load and $93 \%$ removal of total solids.
\end{abstract}

Keywords: Advanced oxidative processes . 


\section{INTRODUÇÃO}

Um dos grandes problemas da humanidade é a poluição ambiental causada pelas intensas atividades antrópicas, seja em países desenvolvidos ou em desenvolvimento.

Os impactos ambientais causados pelo despejo de efluentes industriais tóxicossem tratamento e gerenciamento adequado são de grande importância. As empresas têm se mostrado cada vez mais preocupadas em buscar alternativas para solucionar os problemas dos tratamentos de efluentes, seja para transmitir uma imagem positiva junto à população e assim se tornarem mais competitivas num mercado que está cada vez mais preocupado com questões ambientais, ou seja, pela diminuição dos passivos ambientais. Os processos de tratamento de efluentes geram custos que podem ser aumentados com as punições definida pela legislação ambiental pelo não atendimento dos padrões de qualidade.

A remoção de poluentes orgânicos em efluentes é um grande desafio tecnológico, pois, os sistemas de tratamentos convencionais muitas vezes não atendem a eficiência exigida pela legislação. Por este motivo uma série de estudos científicos tem sido utilizada como ferramenta no desenvolvimento de novas tecnologias e processos ambientalmente corretos.

Nos efluentes industriais os compostos estão geralmente presentes como misturas dificultando a sua caracterização e, muitas vezes, são constituídos por substâncias recalcitrantes, de difícil degradação e tóxicas, inviabilizando tratamento biológico. Além disso, envolvem custos altos, e muitas vezes os efluentes são gerados por processos que tem variabilidade, podendo mudar de um dia para o outro ou até no mesmo dia, dependendo do que esteja sendo produzido (TEIXEIRA, 2002).

A poluição dos corpos d'água está intimamente relacionada, inclusive, com a produção industrial, pois geralmente não há tratamento dos resíduos e, quando há tratamento este - geralmente - não é o adequado. Visando reduzir os impactos ambientais referentes a despejos de resíduos e a adequação destes aos padrões de lançamento, é necessário o tratamento prévio antes de sua disposição final.

Dentro deste contexto, o setor têxtil apresenta um especial destaque, devido à geração de grandes volumes de efluentes, que quando não corretamente tratados, podem causar sérios problemas de contaminação ambiental (KUNZ et al., 2002). Os efluentes têxteis são tóxicos e na maioria dos casos não-biodegradáveis (SCHRANK et al., 2005).

Essa não-biodegradabilidade do efluente é causada, inclusive, pela presença de corantes. Os corantes são responsáveis pela cor no efluente têxtil. Os mais usados pela indústria têxtil são os corantes reativos, pois possui boa estabilidade durante o processo e por ser de simples utilização. Porém são altamente solúveis em água e possui baixa fixação (ARAUJO e YOKOHAMA, 2005) - cerca de $25 \%$ - pelas fibras, sendo boa parte perdida como efluente.

Os corpos d'água contaminados com corantes diminuem a passagem da radiação solar na água reduzindo a atividade dos organismos fotossintéticos e a solubilidade dos gases, provocando alterações e o desequilíbrio da biota aquática e, em alguns casos, a toxicidade aguda e crônica desses ecossistemas. Esses compostos podem permanecer por cerca de cinquenta anos em ambientes aquáticos, pondo em risco a estabilidade desses ecossistemas e a vida em seu entorno (ZANONI e CARNEIRO, 2001).

Esse despejo possui grande quantidade de poluentes, valor elevado de $\mathrm{DQO}, \mathrm{pH}$ flutuante, quantidades consideráveis de sólidos.

Os processos de tratamento mais amplamente utilizados são os fisico-químicos e biológicos. Geralmente, as indústrias têxteis no Brasil tratam seus efluentes empregando a tecnologia de lodos ativados, sendo necessária a aplicação de tratamentos adicionais para a redução da cor. Porém estudos mostram que os corantes reativos são resistentes à degradação biológica, devido à sua estrutura complexa, Em contrapartida, os tratamentos físico-químicos vêm sendo utilizados como alternativa para remover a cor nos efluentes, todavia esse tratamento apenas transfere o corante de fase, não resolvendo diretamente o problema.

Técnicas como a adsorção, adsorção em carvão ativado, coagulação/floculação (LEE et al., 2006), ultrafiltração e osmose reversa têm sido relatadas para a remoção de corantes têxteis. No entanto, além de serem mais dispendiosas do que os processos biológicos realizam apenas a transferência de fase do poluente, e necessitam de pós-tratamento dos resíduos sólidos gerados ou regeneração do material adsorvente.

Os Processos Oxidativos Avançados (POA) são processos físico-químicos que quando aplicados ao tratamento de efluentes, são capazes de produzir mudanças nas estruturas químicas dos contaminantes (MOMENTI, 2006). 
Todos os POA, apesar de utilizarem meios diferentes reacionais, possuem a mesma característica química: produção de radicais hidroxilas $(\bullet \mathrm{OH})$. Os $\bullet \mathrm{OH}$ são espécies altamente reativas, de pequena seletividade, que atacam a maior parte das moléculas orgânicas e inorgânicas, resultando como produtos finais, após uma série de reações intermediárias, em $\mathrm{CO}_{2}$ e $\mathrm{H}_{2} \mathrm{O}$ e sais inorgânicos (RODRÍGUEZ, LEGRINI, OLIVEROS e BRAUN, 1993; ANDREOZZI, INSOLA et al., 1999, apud FARAH, 2007). Esses radicais podem ser formados por vários processos que podem ser classificados em sistemas homogêneos ou heterogêneos, conforme a ausência ou a presença de catalisadores na forma sólida, além de poderem estar ou não sob irradiação (Teixeira e Jardim, 2004). São processos limpos e não seletivos, podendo degradar inúmeros compostos, independente da presença de outros (TEIXEIRA, 2002).

Os radicais hidroxila podem ser gerados por reações envolvendo oxidantes fortes $\left(\mathrm{O}_{3}\right.$ e $\mathrm{H}_{2}$ ? $\left.\mathrm{O}_{2}\right)$, semicondutores $\left(\mathrm{TiO}_{2}, \mathrm{ZnO}\right.$ ) e radiação ultravioleta (UV) (MANSILLA et al., 1997, apud Teixeira, 2002). Eles podem ser usados para destruir compostos orgânicos tanto em fase aquosa, gasosa ou adsorvidos numa matriz sólida.

O radical hidroxila apresenta o segundo maior potencial redox $(2,80 \mathrm{~V})$ conhecido, só perdendo para o Flúor (3,03 V) (TEIXEIRA e JARDIM, 2004).

A constante de velocidade de reação do radical hidroxila na degradação de contaminantes orgânicos, geralmente, está na faixa de $10^{6} \mathrm{a}^{1} 0^{9} \mathrm{~mol}^{-1} \mathrm{~L} \mathrm{~s}^{-1}$ (ANDREOZZI, CAPRIO, INSOLA et al., 1999, apud FARAH, 2007), e os mecanismos que envolvem essas reações são: adição eletrofílica, abstração do hidrogênio e transferência de elétrons.

De acordo Teixeira e Jardim (2004), os processos oxidativos avançados apresentam uma série de vantagens: mineralizam o poluente e não somente o transferem de fase; muito utilizados para compostos refratários transformando-os em biodegradáveis; podem ser usados com outros processos (pré e pós-tratamento); tem forte poder oxidante, com cinética de reação elevada; geralmente não necessitam um pós-tratamento ou disposição final. Os POAs, em associação com processos biológicos convencionais podem resultar em economia e eficiência no tratamento de efluentes com vistas a sua reutilização (FERREIRA, 2005).De acordo com MOMENTI (2006), os POA parecem ser especialmente úteis quando combinados com os processos biológicos, seja como pré-tratamento, para quando existirem contaminantes resistentes à biodegradação, ou como processo de pós-tratamento para efetuar um polimento no efluente antes do descarte nos corpos receptores.De acordo com (VIDAL et al., 2004, apud MOMENTI, 2006), verificou-se que para efluente de curtume, uma sequência de tratamento que utilizava um pré-tratamento com POA, seguido de processo biológico aeróbio, produzia remoção de DQO de $96 \%$, comparada com $60 \%$ sem o pré-tratamento.

\subsection{Fotocátalise Homogênea}

Segundo Mattos et al.(2003) o peróxido de hidrogênio é um dos oxidantes mais versáteis encontrados no mercado, superior ao cloro e dióxido de cloro, por exemplo. Quanto irradiado libera o radical hidroxila, com reatividade inferior apenas ao flúor.

Apesar de seu alto poder de reação, o peróxido de hidrogênio é um metabólito natural em muitos organismos e, quando decomposto, resulta em oxigênio molecular e água. É reconhecidamente citado como o oxidante mais eficiente na conversão de $\mathrm{SO}_{2}$ em $\mathrm{SO}_{4}^{2-}$, um dos maiores responsáveis pela acidez das águas de chuva (PEÑA et al., 2001 e LEE et al., 1990).

O peróxido de hidrogênio é um reagente transparente, possui aparência de água e odor característico. Miscível em água em todas as proporções e não é inflamável. A temperatura ambiente ele é estável se adequadamente armazenados, porém perdas de até $1 \%$ podem ocorrer decorrentes do armazenamento.

A comercialização de peróxido de hidrogênio no Brasil é controlada dependendo de sua concentração. Nasconcentrações mais elevadas, como 90\%, a comercialização é restrita às Forças Armadas, pois quando misturados com alguns compostos ele se torna altamente explosivo. Nessa concentração também é usado para a exploração espacial, como fonte de propulsão em foguetes. Também é utilizado como alternativa para o tratamento de efluentes têxteis, de papel e celulose.

A fotoclivagem do $\mathrm{H}_{2} \mathrm{O}_{2}$ pela radiação ultravioleta gera dois radicais hidroxila $(\bullet \mathrm{OH})$ Equação 1 que reagem com os compostos orgânicos para geração de compostos mais simples Equação 2. Porém é importante dizer que quando o $\mathrm{H}_{2} \mathrm{O}_{2}$ está em excesso ele age capturando $\mathrm{OH}^{*}$ Equação 3 , o que diminui a eficiência na mineralização dos compostos orgânicos (ARAUJO E YOKOHAMA, 2005.). 


$$
\begin{aligned}
& \quad \mathrm{H}_{2} \mathrm{O}_{2}+h v \rightarrow 2 O H^{*} \\
& R-C+O H^{*} \\
& \rightarrow \text { ProdutosFinais }
\end{aligned}
$$

$$
\mathrm{H}_{2} \mathrm{O}_{2}+\mathrm{OH}^{*} \rightarrow \mathrm{OH}_{2}^{*}+\mathrm{H}_{2} \mathrm{O}
$$

Entre outras aplicações do peróxido de hidrogênio destaca-se o controle de odores (WANNOWIUS et al., 1999), redução da demanda química e bioquímica de oxigênio, controle de bio-processos, desinfecção, oxidação de componentes orgânicos, entre outros.

\subsection{Fotocatálise heterogênea}

Os sistemas heterogêneos se diferenciam dos homogêneos devido à presença dos catalisadores semicondutores, geralmente na forma sólida, formando um sistema de mais de uma fase. De acordo com Nogueira, Jardim (1998), $\mathrm{TiO}_{2}$, entre outros semicondutores como Cds, $\mathrm{ZnO}, \mathrm{WO}_{3}, \mathrm{ZnS}, \mathrm{FeO}_{3}$, podem agir com sensibilizadores em processos de oxidação e redução mediados pela luz devido a sua estrutura eletrônica. Entre os semicondutores, o dióxido de titânio é o mais extensivamente estudado devido principalmente às sua não toxicidade, fotoestabilidade e estabilidade química em uma ampla faixa de $\mathrm{pH}$. $\mathrm{O} \mathrm{TiO}_{2}$ existe em três formas alotrópicas: anástase, rutilo e brookite, sendo as duas primeiras asmaiscomuns. Existem preparações de $\mathrm{TiO}_{2}$ que possuem as duas fases, e muitos desse catalisadores apresentam uma atividade catalítica superior a qualquer uma das fases individuais. $\mathrm{O}$ exemplo mais conhecido é o Degussa P25R, com aproximadamente $70 \%$ anatase e $30 \%$ rutila. As razões para a melhor atividade de materiais contendo ambas as fases em comparação com uma única fase não foramestabelecidas.

Além disso, segundo Nogueira, Jardim (1998), muitos catalisadores têm sido testados, sendo o dióxido de titânio, na forma cristalina anatase, o que parece ter características mais importantes, como alta estabilidade, bom desempenho e baixo custo.

Os semicondutores que atuam como fotocatalisadores possuem duas regiões energéticas: a região de energia mais baixa é a banda de valência (BV), onde os elétrons não possuem movimento livre e a região de energia mais alta é a banda de condução (BC), onde os elétrons são livres para se moverem através do cristal, produzindo condutividade elétrica similar aos metais (TEIXEIRA e JARDIM, 2004). Entre essas duas regiões existe a zona de "band-gap". A energia de "band-gap" é a energia mínima necessária para excitar o elétron e promovê-lo de uma banda de menor para outra de maior energia.

De maneira geral, o processo é baseado na irradiação de um fotocatalisadorque adsorve energia do fóton maior ou igual à energia do "band gap" do semicondutor para provocar a transição eletrônica. O elétron, sob irradiação, é promovido da banda de valência (BV) para a banda de condução (BC) formando sítios oxidantes e redutores que catalisam reações químicas, oxidando compostos orgânicos até $\mathrm{CO}_{2}$ e $\mathrm{H}_{2} \mathrm{O}$, e reduzindo metais dissolvidos ou outras espécies presentes (FERREIRA, 2005). De acordo com Nogueira e Jardim (1997), algumas classes de compostos passíveis de degradação por fotocatálise são alcanos, cloroalifáticos, álcoois, ácidos carboxílicos, fenóis, clorofenóis, herbicidas, surfactantes e corantes. Além de contaminantes orgânicos, compostos inorgânicos como $\mathrm{HCN} \mathrm{e} \mathrm{H}_{2} \mathrm{~S}$ também são passíveis de fotooxidação, sendo destruídos com boa eficiência com relação aos métodos de oxidação convencionais.

Segundo Nogueira e Jardim (1997), a fotocatálise heterogênea tem apresentado grande eficiência na destruição de várias classes de compostos orgânicos voláteis em fase gasosa incluindo álcoois, cetonas, alcanos, alcenos clorados e éteres, com potencialidade de aplicação à remediação de solos e águas contaminadas, bem como desodorização de ambientes.

$\mathrm{Na}$ fotocatálise heterogênea, o oxigênio apresenta-se como importante constituinte para a reação. Os radicais hidroxil e radicais superóxidos são as espécies oxidantes primárias no processo de oxidação fotocatalítica. A eficiência dessas reações na degradação depende da concentração de 
oxigênio dissolvido (SAUER, 2002).

A presença de grandes quantidades de óleos, graxas e sólidos, interferem na vida útil das fontes de radiação UV, pois estas se aderem à sua superfície inviabilizando a passagem da radiação. Dessa forma impossibilita a utilização das lâmpadas submersas, reduzindo, assim, o volume tratado.

A presença de sólidos grosseiros na superfície da lâmina d'água impede a passagem da radiação e seu contato com o agente oxidante.

Contudo, de uma maneira geral, devido ao fato de o catalisador estar homogeneizado no efluente, o contato da radiação com o catalisador ocorre facilitadamente.

\section{METODOLOGIA}

A montagem do reator e os testes executados foram realizados nas dependências da FCT/ UNESP de Presidente Prudente, no Laboratório de Tratamento de Efluentes. Foi utilizado peróxido de hidrogênio comercial (35 \% Yuan LongChem) com concentração de 2,68\% onde foi diluído no efluente para obter concentrações de $1,40 \%, 1,10 \%$ e $0,90 \%$ de oxidante.

Duas soluções a $1,40 \%$ de oxidante foram preparadas e recirculadas no reator fotocatalítico inicialmente com vazão de $90 \mathrm{~L} . \mathrm{h}^{-1}$ e posteriormente com vazão de $30 \mathrm{~L} \cdot \mathrm{h}^{-1}$, a fim de se determinar o tempo de detenção hidráulica.Após definido o TDH, este valor foi utilizado para todos os experimentos subseqüentes.

Foi utilizado efluente industrial do curtume de semi-acabamento e acabamento Touro localizado em Presidente Prudente SP (produção de 1300 peles.dia $^{-1}$ ), e placas de vidro onde foi imobilizado o dióxido de titânio com densidade de $10 \mathrm{~g} \cdot \mathrm{m}^{-2}$, de forma análoga à Maciel et al. (2010). Essa metodologia foi utilizada em escala piloto no reator fotocatalítico e em seguida comparada com a fotocatálise homogênea.

No reator fotocatalítico foram utilizados 60 litros de efluente bruto e as placas de vidro, onde foram recirculados pelo período determinado pelo TDH.

Foram utilizadas 32 placas de vidro jateadas, de $15 \times 10 \mathrm{~cm}$, previamente pesadas. Preparou-se uma suspensão $10 \%$ de $\mathrm{TiO}_{2}$ em água destilada e, logo em seguida, aplicou-se a suspensão sobre a placa de vidro (lado jateado).

Posteriormente as placas foram deixadas na posição vertical para o escoamento do excesso, pela gravidade durante um minuto. Em seguida foi fixado utilizando soprador térmico a uma altura de $30 \mathrm{~cm}$ por $1,5 \mathrm{~min}$. Ao final do procedimento as placas foram pesadas. Este procedimento foi repetido quatro vezes, até a placa atingir uma camada de 10g. $\mathrm{m}^{-2}$ (MACIEL et al., 2010).

$\mathrm{Na}$ etapa com fotoclivagem com peróxido de hidrogênio foi utilizado o reator fotocatalítico com altura da lâmina d'água limitada até a lâmpada, visando à integridade da mesma. O volume total utilizado foi de $42 \mathrm{~L}$. O efluente bruto e concentrações de peróxido de hidrogênio foram testadas.

Foram feitas diluições do efluente bruto, advindo do curtume Touro, com a solução de peróxido de hidrogênio a 2,68\% para obter concentrações finais de 1,40\%, 1,10\% e 0,90\%. A Tabela 1 apresenta os volumes utilizados de solução $\mathrm{H}_{2} \mathrm{O}_{2}$, após a determinação de concentração de $\mathrm{H}_{2} \mathrm{O}_{2}$, e de efluente bruto usados para obter as concentrações necessárias.

Tabela 1: Relação de peróxido de hidrogênio e efluente utilizada no reator.

\begin{tabular}{|l|l|l|l|}
\hline \multirow{2}{*}{ Concentração $\left(\mathrm{H}_{2} \mathrm{O}_{2}\right)$} & \multicolumn{2}{|l|}{ Volume (L) } & \multirow{2}{*}{ Total (L) } \\
\cline { 2 - 4 } & Sol. $\mathrm{H}_{2} \mathrm{O}_{2}$ & Efluente & \\
\hline Fotólise & 0 & 42 & 42 \\
\hline 1,40 & 22 & 20 & 42 \\
\hline 1,10 & 17,6 & 24,4 & 42 \\
\hline 0,90 & 14,1 & 27,9 & 42 \\
\hline
\end{tabular}


Para determinar a concentração de peróxido de hidrogênio houve a necessidade de se padronizar a solução de permanganato de potássio. A Equação 4 mostra a reação de óxido redução na titulação da solução de oxalato de sódio com permanganato de potássio.

$$
\begin{aligned}
& 5 \mathrm{Na}_{2} \mathrm{C}_{2} \mathrm{O}_{2}+2 \mathrm{KMnO}_{4} \\
&+ 8 \mathrm{H}_{2} \mathrm{SO}_{4} \rightarrow \\
& \mathrm{K}_{2} \mathrm{SO}_{4}+2 \mathrm{MnSO}_{4} \\
&+ 5 \mathrm{Na}_{2} \mathrm{SO}_{4}+10 \mathrm{CO}_{2} \\
&+ 8 \mathrm{H}_{2} \mathrm{O}
\end{aligned}
$$

O reator fotocatalítico é constituído em aço galvanizado de medidas externas de 90 x 20 x 41 $\mathrm{cm}$ (comprimento, altura e largura, respectivamente), onde foram fixadas seis lâmpadas de vapor de mercúrio a baixa pressão de $15 \mathrm{~W}$ (marca CSR), que emitem radiação em um comprimento de onda compreendido entre 100 e $254 \mathrm{~nm}$ e uma base de madeira para fixação de reatores das lâmpadas. $\mathrm{O}$ reator tem a capacidade de tratar $42 \mathrm{~L}$ de efluente, podendo operar em batelada, com os registros fechados ou ainda em fluxo contínuo, com os registros abertos e um reservatório de alimentação.

A Figura 1 mostra o desenho do reator com suas medidas.

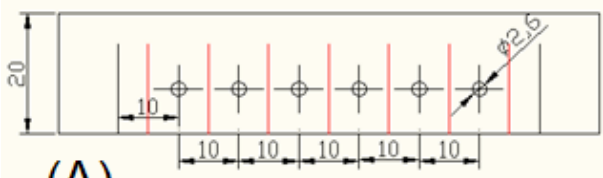

(A)

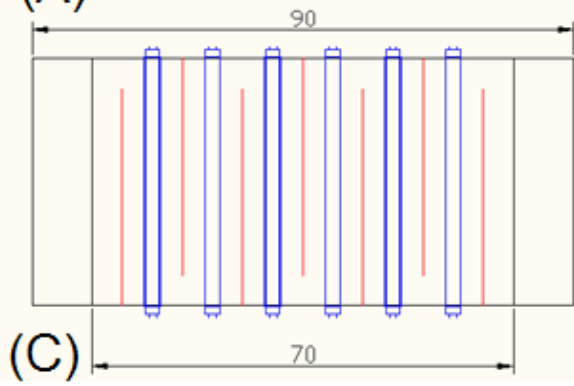

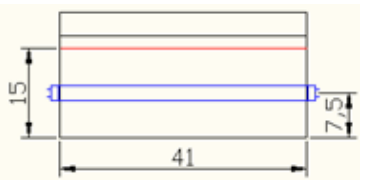

(B)

Figura 1: Esquema do reator.

(A): Vista lateral do reator;

(B): Vista superior de uma das chicanas;

(C): Vista superior de todo o reator.

Para determinar o tempo de detenção hidráulica, duas soluções $1,40 \%$ de peróxido de hidrogênio com volume total de $42 \mathrm{~L}$ foram feitas. Estas soluções foram recirculadas no reator, uma com vazão de $90 \mathrm{~L} \cdot \mathrm{h}^{-1}$ e outra com vazão de $30 \mathrm{~L} \cdot \mathrm{h}^{-1}$. A cada hora alíquotas foram colhidas para posterior análise de absorbância em espectrofotômetro.

No teste em escala piloto para a fotocatálise heterogênea as placas de vidro com o catalisador foram fixadas nos suportes com prendedores em aço galvanizado em que foram utilizados $60 \mathrm{~L}$ de efluente bruto. Esse teste durou $4 \mathrm{~h}$ e foram tiradas amostras para análise em espectrofotômetro a cada $1 \mathrm{~h}$, juntamente com leitura de temperatura, OD e análise de DQO.

Para a fotoclivagem com peróxido de hidrogênio, as soluções com volumes de $42 \mathrm{~L}$ foram recirculados pelo período definido pela TDH, contendo diferentes concentrações de $\mathrm{H}_{2} \mathrm{O}_{2}(1,40 \%, 1,10 \%$ e $0,90 \%)$. A cada hora alíquotas foram retiradas para análise, e feitas leituras de $\mathrm{pH}$ e temperatura.

$\mathrm{O} \mathrm{pH}$ foi analisado a temperatura ambiente pelo método potenciométrico, utilizando um potenciômetro (Hanna) calibrado com soluções tampão com pH 4 e 7 (Synth),

A temperatura e o oxigênio dissolvido foram medidos por meio de oxímetro que utiliza o método potenciométrico. Foi utilizado um oxímetro portátil que media o oxigênio dissolvido e a temperatura ao mesmo tempo. 
A concentração de OD e DQO foram determinadas seguindo os métodos 4500O-G e5220D, do Standard Methods for WaterandWastewaterAnalysis APHA,AWWA, WPCF (1995), respectivamente.

As analises de sólidos foi feita através de metodologia do Standard Methods (APHA, AWWA, WPCF, 1995).

Por se tratar de efluente bruto é difícil a construção de uma curva de calibração, pois possui bastante quantidade de sólidos que dificultam a leitura pelo espectrofotômetro. Dessa forma, neste estudo buscou apenas a determinação da porcentagem de degradação na cor e não na concentração de corante removida.

Para tal, foram feitas leituras de absorbância, em espectrofotômetro (Femto 700S; $200<\lambda<1100$; cubeta em vidro óptico passo $10 \mathrm{~mm}$ ), em um comprimento de onda específico na região de maior resposta espectral, onde foram feitas as leituras das alíquotas e posterior comparação entre elas quanto ao valor lido.

\section{RESULTADOS}

\subsection{Fotocatálise heterogênea}

A variação de absorbância pelo tempo, representada pela Figura 2, demonstrou que esta metodologia se mostrou indiferente.

Isso ocorre devido ao valor elevado de sólidos totais presente nesses efluentes e, durante a degradação no reator esses sólidos decantam e se depositam na superfície do semicondutor, impossibilitando sua ativação pela radiação, e em volta das lâmpadas, impossibilitando que a radiação seja liberada para o meio.

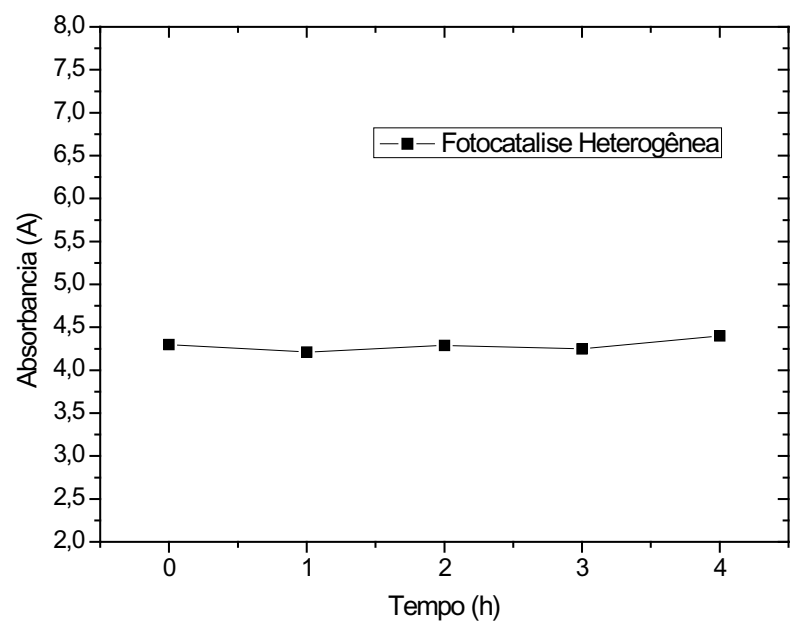

Figura2: Variação de absorbância x tempo na fotocatálise heterogênea.

Dessa forma, pode-se observar que a submersão das lâmpadas se torna inviável, pois o efluente se mostra destrutivo para elas devido especialmente à grande quantidade de óleos e graxas. Essas substâncias se aderem às lâmpadas formando uma camada espessa que não são possíveis de remover.

Apesar de não apresentar um bom resultado neste estudo, outros trabalhos como o realizado por Pascoal (2007) puderam comprovar a eficiência da fotocatálise heterogênea no tratamento de efluentes industriais com significativa concentração de matéria orgânica e $\mathrm{Cr}(\mathrm{VI})$. Observou-se também nesse trabalho, um melhor desempenho quando a fonte luminosa é o sol, uma vez que os resultados obtidos pelos autores mostraram constantes cinéticas de pseudo-primeira ordem mais elevadas.

$\mathrm{Na}$ Figura 3 pode ser observado que na fotólise, o $\mathrm{pH}$ teve variações entre 5,75 e 6,07, de onde se conclui que a radiação UV pouco age nesse parâmetro.

Já nos experimentos envolvendo a adição de peróxido de hidrogênio é possível notar que o $\mathrm{pH}$ cai ao longo do tempo e, quanto maior a concentração de deste oxidante mais ele tende a cair. Esse fato se mostra relevante, pois experimentos realizados por Schrank et al. (2005) mostraram que a melhor eficiência na fotoclivagem com $\mathrm{H}_{2} \mathrm{O}_{2}$ se encontra com o $\mathrm{pH}$ na faixa de 3 . 


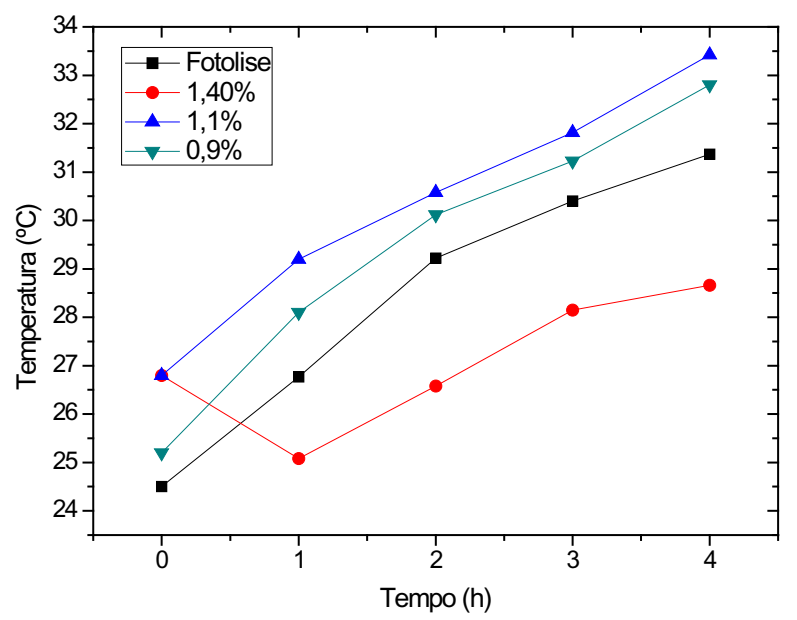

Figura 3:Variação da temperatura ao longo do tempo de operação do sistema.

A Tabela 2 mostra a variação na DQO nos experimentos realizados.

Tabela 2: Demanda química de oxigênio.

\begin{tabular}{|l|l|l|l|l|}
\hline & Fotolise & $1,40 \%$ & $1,10 \%$ & $0,90 \%$ \\
\hline Inicial(mg. $\left.\mathrm{L}^{-1}\right)$ & 14.120 & 14.120 & 19.385 & 14.120 \\
\hline Final (mg. $\left.\mathrm{L}^{-1}\right)$ & 13.681 & 7.861 & 13.945 & 11.374 \\
\hline Remoção (\%) & 3,1 & 44,3 & 28,1 & 19,5 \\
\hline
\end{tabular}

Pela Tabela 2 conclui-se que o efluente proveniente do tingimento do couro possui grande carga de DQO, chegando a $14.000 \mathrm{mg} \cdot \mathrm{L}^{-1}$. Na fotólise houve pouca variação, caracterizada pelo erro experimental e operacional. Já nos experimentos envolvendo $\mathrm{H}_{2} \mathrm{O}_{2}$ a variação foi significativa, em especial para o experimento com concentração de $1,40 \%$. Tabela 3.

Outro parâmetro importante que analisado, foi os sólidos totais, os dados são apresentados na

Tabela 3: Sólidos totais.

\begin{tabular}{|l|l|l|l|l|}
\hline & Fotólise & $1,40 \%$ & $1,10 \%$ & $0,90 \%$ \\
\hline Inicial (mg/L) & 1.590 & 1.590 & 2.322 & 1.590 \\
\hline Final (mg/L) & 1.468 & 101 & 995 & 1.090 \\
\hline Remoção (\%) & 7,7 & 93,6 & 57,2 & 31,4 \\
\hline
\end{tabular}

Ao analisar a Tabela 3 é possível observar a melhora significativa no experimento contendo $1,40 \%$, enos experimentos de $1,10 \%$ e $0,90 \%$ também houveramremoções consideráveis.

Esses sólidos foram convertidos em $\mathrm{CO}_{2}, \mathrm{H}_{2} \mathrm{O}$ e outros compostos inorgânicos. Também ocorreu flotação, devido à formação de bolhas que emergiram carregando consigo partículas de sólidos. Entretanto não foi possível identificar outros fatores que justifiquem o ocorrido. Esse mesmo fenômeno ocorreu em todos os experimentos, exceto na fotólise.

A Figura 4 mostra o gráfico da variação da absorbância, em comprimento de onda igual a 550 nm, com o tempo.

Observa-se a variação significativa de absorbância no início de funcionamento do reator nos experimentos com a presença do oxidante. Isso ocorre devido à diluição do efluente bruto com a solução $2,68 \%$ de peróxido de hidrogênio.

No experimento com $1,40 \%$ houve o melhor resultado, onde a absorbância reduziu de 4,40A para $0,17 \mathrm{~A}$, o que representa uma diminuição de $96,17 \%$, onde sua aparência se aproxima a da água 


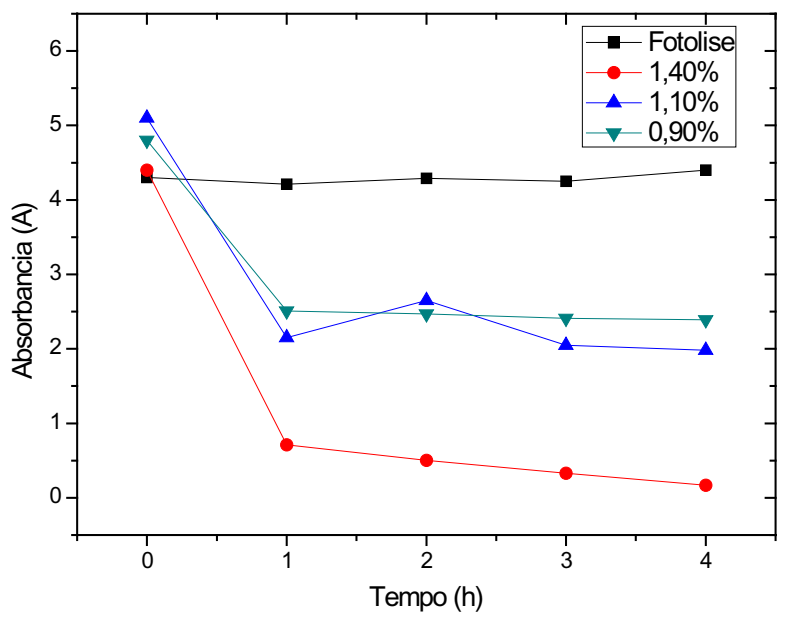

Figura 4: Variação da absorbância o longo do tempo de operação do sistema.

potável. Apesar de apresentar grande variação na primeira hora, devido à diluição, houve remoção de $76,18 \%$ da primeira hora até o final do experimento.

Já no experimento com 1,10\%, também houve redução na absorbância de 5,10A para 1,98A, sendo que desta variação, $94,54 \%$ ocorreu devido à diluição. Ao final das 4 horas houve remoção total de $61,18 \%$, porém apresentou apenas $8 \%$ de degradação a partir da primeira hora de funcionamento.

No último experimento, de $0,90 \%$, houve redução total de $4,80 \mathrm{~A}$ para $2,39 \mathrm{~A}$, o que representou uma diminuição de $50,20 \%$, sendo que desta variação $94,88 \%$ ocorreram pela diluição e, apenas $4,78 \%$ a partir da primeira hora.

O experimento com $0,90 \%$ e $1,10 \%$ de oxidante mostraram-se praticamente indiferentes quanto à remoção de cor, já o com $1,40 \%$ possui uma remoção total de $96,17 \%$.

Foi grande alteração nas propriedades organolépticas, principalmente quanto à diminuição de cor e no odor, onde o odor característico não foi mais percebido.

\section{CONSIDERAÇÕES FINAIS}

A fotocatálise heterogênea $\left(\mathrm{TiO}_{2} / \mathrm{UV}\right)$ se mostrou ineficaz para o tratamento do efluente, pois este apresenta grande concentração de óleos e graxas, os quais causam uma diminuição da eficiência do semi-condutor e das lâmpadas ultravioletas.

A fotólise por si só não apresentou eficiência adequada. Em contra partida, o reator fotocatalítico aliado à radiação ultravioleta e peróxido de hidrogênio se mostrou bastante eficiente na remoção de cor, principalmente quanto à rapidez na degradação.

O experimento envolvendo $1,40 \%$ de oxidante foi o que obteve melhores resultados, chegando à remoção de $96 \%$ na absorbância, 44\% de remoção de matéria orgânica e $93 \%$ de remoção de sólidos.

Apesar dos resultados serem satisfatórios, pouco se sabe quanto à influência dos parâmetros analisados na eficiência, ou na velocidade, do tratamento. Dessa forma, é sugerido para os trabalhos futuros o controle de alguns parâmetros a fim de determinar a influência de cada um na eficiência e na cinética de reação quando são mantidos constantes, ou quando são variados.

No presente trabalho não se levou em consideração as análises de toxicidade e a formação de subprodutos, sendo de grande importância a determinação destes itens para a destinação dos efluentes tratados, considerando os padrões de qualidade da água sempre de acordo com a legislação vigente.

\section{REFERÊNCIAS}

APHA, AWWA, WPCF. 1995 Standard Methods for the Examination of Water and Wastewater, 19th edition, American Public Health Association, Washington. 
TEIXEIRA, C. R. A. B. Estudo comparativo de tipos diferentes de processos oxidativos avançados. 2002. Tese (Doutorado em Engenharia Civil). Universidade Estadual de Campinas, Campinas, São Paulo.

FARAH, C. R. T. Conjugação de processos físico-químicos (UV; H2O2; UV/H2O2; reagente de Fenton; fotoFenton) e biológico (lodos ativados) para tratamento de águas residuárias contendo formol. 2007. Tese (Doutorado em Engenharia Civil). Universidade Estadual de Campinas, Campinas, São Paulo.

TEIXEIRA, C. P. A. B.; JARDIM, W. F. Processos oxidativos avançados: conceitos teóricos. CadernoTemático 3. 2004, Campinas, São Paulo.

RODRÍGUES, M. Fenton and UV-vis based advanced oxidation processes in wastewater treatment: Degradation, mineralization and biodegradability enhancement. Tese (Doutorado em engenharia química ambiental). Universidade de Barcelona, Barcelona, 2003.

SCHRANK, S G.; SANTOS, J. N. R. dos; CARVALHO, J. B. R. Degradação do corante têxtil LUMACRON $\mathrm{SE}$ utilizando H2O2/UV. XXIII Congresso Brasileiro de Engenharia Sanitária e Ambiental, ABES, Rio de Janeiro, p. 1-5, 2005.

KUNZ, A.; PERALTA-ZAMORA, P.; MORAES, S. G.; DURÁN, N. . Novas Tendências no Tratamento de Efluentes Têxteis. Química Nova, São Paulo, v.25, n.1, p.78-82, 2002.

MOMENTI, T. J; Processo anaeróbico com Processos Oxidativos Avançados (POA) no tratamento dos efluentes do processo industrial de branqueamento da polpa celulósica. 2006. Tese (Doutorado em hidráulica e saneamento). Universidade de São Paulo, São Carlos, São Paulo.

ARAÚJO, F. V. F.; YOKOHAMA, L.; Remoção de cor em soluções de corantes reativos por oxidação com H2O2/UV. Química Nova, jan/fev. v.29 N1, p. 11-14, 2005.

ZANONI, M.V.B; CARNEIRO, P.A. Prevenção e tratamento de resíduos antes da liberação no ambiente devem ser metas da indústria - o Uso descarte dos Corantes têxteis, Ciência Hoje, vol. 29, n. 174, p. 61-64, agosto de 2001.

MATTOS, I. L. de; SHIRAISHI, K. A.; BRAZ, A. D.; FERNANDES, J. R. Peróxido de hidrogênio: importancia e determinação. Química Nova, v. 26, n. 3, p. 373-80, 2003.

PEÑA, R. M.; GARCIA, S.; HERRERO, C.; LUCAS, T. Atmos. Environ, v. 35, p. 209, 2001.

LEE, J. H.; TANG, I. N.; WEINSTEIN-LLOYD, J. B.Anal Chemistry, v. 62, p. 2381, 1990.

FERREIRA, I. V. L. Fotocatálise Heterogênea com TiO2 Aplicada ao Tratamento de Esgoto Sanitário Secundário. São Carlos. Tese (Doutorado) - Escola de Engenharia de São Carlos, Universidade de São Paulo. São Carlos, SP, 2005.

SAUER, T. Tratamento de efluentes de curtumes através do processo combinado de degradação fotocatalítica seguida por adsorção em carvão ativado. Florianópolis. Tese (Doutorado) - Universidade Federal de Santa Catarina, 2002.

NOGUEIRA, R. F. P.; Jardim, W. F.; A fotocatálise heterogênea e suaaplicação ambiental. Quím Nova. 1998; 21: 69-72.

MACIEL, H. P.; TERAN, F. J. C.; TAKASHI, R. K.; SHINOHARA, G. M. M. Aplicação de fotocatálise heterogénea com TiO2 para o tratamento de residuo de corante de industria de tingimentocouro. XXXIICongresso Interamericano de EngenhariaSanitária e Ambiental (AIDIS), 2010, República Dominicana.

PASCOAL, S. A.; Aplicação de Radiação UV solar e Artificial no Tratamento Fotocatalítico de Efluentes de Curtume. Quim. Nova, Vol. 5. 2007. 